\title{
The discovery of glycolaldehyde in a star forming region
}

\author{
Maria T. Beltràn ${ }^{1}$, Claudio Codella ${ }^{1}$, Serena Viti ${ }^{2}$ \\ Roberto Neri $^{3}$ and Riccardo Cesaroni ${ }^{1}$ \\ ${ }^{1}$ Arcetri Observatory (Italy), ${ }^{2} \mathrm{UCL}$ (UK), ${ }^{3}$ IRAM (France)
}

\begin{abstract}
Glycolaldehyde is the simplest of the monosaccharide sugars and is directly linked to the origins of life. We report on the detection of glycolaldehyde $\left(\mathrm{CH}_{2} \mathrm{OHCHO}\right)$ towards the hot molecular core G31.41+0.31 through observations with the IRAM PdBI (Plateau de Bure Interferomter) at $1.4,2.1$, and $2.9 \mathrm{~mm}$.
\end{abstract}

The $\mathrm{CH}_{2} \mathrm{OHCHO}$ emission comes from the hottest $(\geqslant 300 \mathrm{~K})$ and densest $\left(\geqslant 2 \times 10^{8}\right.$ $\left.\mathrm{cm}^{-3}\right)$ region closest $\left(\leqslant 10^{4} \mathrm{AU}\right)$ to the (proto)stars. The comparison of data with gasgrain chemical models of hot cores suggests for G31.41+0.31 an age of a few $10^{5} \mathrm{yr}$. We have also shown that only small amounts of CO need to be processed on grains in order for existing hot core gas-grain chemical models to reproduce the observed column densities of glycolaldehyde, making surface reactions the most feasible route to its formation (Beltràn et al. 2009).

Figure 1 shows the brightness temperature scale of the $\mathrm{CH}_{2} \mathrm{OHCHO}\left(20_{2,18}-19_{3,17}\right)$, $\left(14_{0,14}-13_{1,13}\right)$, and $\left(10_{1,9}-9_{2,8}\right)$ at $220463.87,143640.94$, and $103667.91 \mathrm{MHz}$, respectively, as observed towards the central position of the G31.41+0.31 hot core - see Beltràn et al. 2009 for details. Rest frequencies are pointed out by vertical bars.

- Upper panel: the glycolaldehyde line is blended with the $\mathrm{CH} 3 \mathrm{CN}(12-11 ; \mathrm{K}=8)$ line. Two additional lines are present: (i) ${ }^{13} \mathrm{CH}_{3} \mathrm{CN}\left(12_{6}-11_{6}\right.$; labeled by $\mathrm{K}$ '), and (ii) $\mathrm{HCOOCH}_{3}$-A $\left(25_{11,15}-26_{9,18}\right)(2204445.79 \mathrm{MHz} ; \mathrm{Eu}=272 \mathrm{~K})$ which could contain an emission contribution due to the $\mathrm{CH}_{2} \mathrm{OHCHO}\left(18_{4,14}-17_{4,13}\right)(220433.51 \mathrm{MHz}$; Eu= $108 \mathrm{~K}$ ) line. The continuous line shows the fit to the group of three lines formed by the $\mathrm{CH}_{2} \mathrm{OHCHO}\left(20_{2,18}-19_{3,17}\right), \mathrm{CH}_{3} \mathrm{CN}(12-11 ; \mathrm{K}=8)$, and ${ }^{13} \mathrm{CH}_{3} \mathrm{CN}(12-11 ; \mathrm{K}=6)$; the dotted lines draw the three individual Gaussian curves used for the fit.

- Middle panel: the $\mathrm{CH}_{2} \mathrm{OHCHO}$ line is part of a spectral pattern containing also the $\mathrm{HCCC}^{13} \mathrm{CCN}(143636.63 \mathrm{MHz} ; \mathrm{Eu}=183 \mathrm{~K}), \mathrm{C}_{2} \mathrm{H}_{3} \mathrm{CN}\left(33_{2,31}-32_{4,28}\right.$ (143646.50 MHz; $\mathrm{Eu}=620 \mathrm{~K})$, and $\mathrm{C}_{2} \mathrm{H}_{5} \mathrm{OH}\left(29_{2,28}-28_{3,26}(143651.78 \mathrm{MHz} ; \mathrm{Eu}=415 \mathrm{~K})\right.$ lines. The results of the fit as drawn as in the upper panel.

- Lower panel: besides the glycolaldehyde emission, an unidentified spectral pattern is present around $103674 \mathrm{MHz}$. The solid curve shows the fit of the isolated $\mathrm{CH}_{2} \mathrm{OHCHO}$ line.

\section{References}

Beltràn, M., Codella, C., Viti, S., Neri, R., \& Cesaroni, R. 2009, ApJ (Letters) 690, L93 

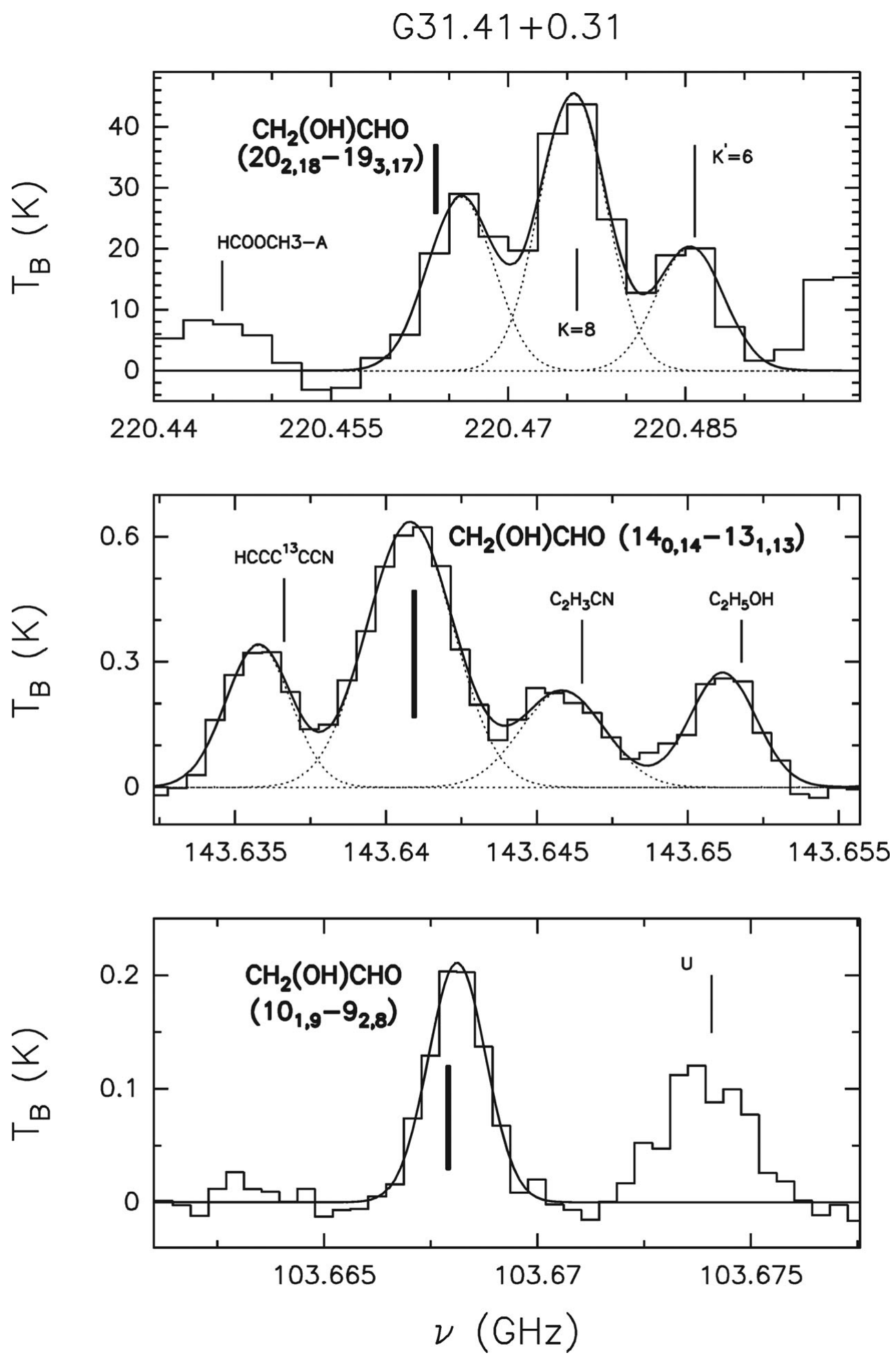

Figure 1. Beam-averaged spectra in the hot core of G31.41+0.31 (after Beltràn et al. 2009) 